\title{
PRODUTIVIDADE E RESISTÊNCIA ÓSSEA DE POEDEIRAS SUPLEMENTADAS COM ALLZYME® SSF NAS DIETAS
}

\author{
PERFORMANCE AND BONE RESISTANCE OF LAYING HENS SUPPLEMENTED WITH \\ ALLZYME®SSF IN THE DIETS
}

\author{
Gentilini, F.P.1* ${ }^{1 *}$ R.A.G. da Silva ${ }^{1 A}$, P.M., Nunes ${ }^{1 B}$, F.M. Gonçalves ${ }^{1 \mathrm{c}}$, C. Kuhn ${ }^{2}$, M.A. Anciuti ${ }^{3}$ \\ e F. Rutz ${ }^{1 D}$
}

\begin{abstract}
1'Departamento de Zootecnia. Campus Universitário s/n. CEP 96010-900. Universidade Federal de Pelotas Capão do Leão, RS. Brasil. *fabianepg@brturbo.com.br; 'Aritinhavet@hotmail.com; Bnunes_perlemm@ yahoo.com.br; ' $f$ medeiros_fv@ufpel.com.br; Dfrutz@alltech.com

${ }^{2}$ CEFET. Bento Gonçalves, RS. Brasil.

${ }^{3}$ Conjunto Agrotécnico Visconde da Graça. Universidade Federal de Pelotas, RS. Brasil. manciuti@ufpel.edu.br
\end{abstract}

\section{PalaVRas chaVe adicionais}

Complexo enzimático. Produtividade. Ossos da tíbia.

\section{RESUMO}

Durante 280 dias, divididos em 10 ciclos produtivos, utilizando 384 poedeiras Hisex Brown, desenvolveu-se um estudo objetivando-se avaliar a contribuição de um complexo enzimático (Allzyme ${ }^{\circledR}$ SSF) com diferentes níveis de valorização energética na dieta sobre o desempenho produtivo, a qualidade dos ovos e a resistência óssea. $O$ delineamento utilizado foi o completamente casualizado, sendo os seguintes tratamentos: T1: dieta basal (controle); T2: dieta basal + Allzyme ${ }^{\circledR} \mathrm{SSF}$ (valorizado em $120 \mathrm{kcal}$ EM/ $\mathrm{kg}$ ); T3: dieta basal + Allzyme ${ }^{\circledR}$ SSF (valorizado em $90 \mathrm{kcal} \mathrm{EM} / \mathrm{kg}$ ); T4: dieta basal + Allzyme ${ }^{\circledR} \mathrm{SSF}$ (valorizado em $60 \mathrm{kcal} \mathrm{EM} / \mathrm{kg}$ ); T5: dieta basal + Allzyme $^{\circledR}$ SSF (valorizado em $30 \mathrm{kcal}$ EM/kg) e T6: dieta basal + Allzyme ${ }^{\circledR}$ SSF (sem valorização energética - on top). Os tratamentos consistiram em dietas a base de milho e farelo de soja, com a inclusão do Allzyme ${ }^{\circledR}$ SSF na matriz nutricional das dietas (150 g/t). Foram avaliadas as variáveis de desempenho consumo de ração $(\mathrm{CR})$, produção diária de ovos (PDOV), conversão alimentar por dúzia (CADZ), peso corporal (PC) e variação do peso corporal (VPC); as variáveis de qualidade dos ovos peso dos ovos (POV), gravidade específica (GE), coloração da gema (CG), unidade Haugh (UH), peso da clara (PCL), peso da gema

Recibido: 2-11-07. Aceptado: 21-2-08.

\section{AdDitionAL KEYWORDS}

Enzyme complex. Productivity. Tibiotarsus.

(PG), peso da casca (PCS) e espessura da casca (ECS); e, a resistência óssea (RO). Os dados foram submetidos à análise estatística utilizando análise de variância a $5 \%$ de probabilidade e teste Tukey, e análise de contrastes simples e múltiplo. Observou-se um menor CR nas aves do T6, que tiveram também diminuídos o POV e PCL. As demais variáveis não sofreram efeito dos tratamentos. Concluiu-se que o Allzyme ${ }^{\circledR} \mathrm{SSF}$ quando adicionado on top propiciou redução no consumo, mas manteve a produção e a resistência óssea.

\section{SUMMARY}

During 280 days, a study was run to evaluate the rol of an enzyme complex (Allzyme ${ }^{\circledR} \mathrm{SSF}$ ) in terms of dietary energy reformulation on productive performance, egg quality and bone strength. 384 Hisex Brown layers divided in 10 productive cycles were used. A completely randomized experimental design was used and treatments consisted of T1: basal diet (control); T2: basal diet + Allzyme ${ }^{\circledR}$ SSF (reformulated to $120 \mathrm{kcal} \mathrm{ME} / \mathrm{kg}$ ); T3: basal diet + Allzyme ${ }^{\circledR} \mathrm{SSF}$ (reformulated to $90 \mathrm{kcal} \mathrm{ME/}$ $\mathrm{kg}$ ); T4: basal diet + Allzyme ${ }^{\circledR} \mathrm{SSF}$ (reformulated to $60 \mathrm{kcal} \mathrm{ME} / \mathrm{kg}$ ); T5: basal diet + Allzyme ${ }^{\circledR} \mathrm{SSF}$ (reformulated to $30 \mathrm{kcal} \mathrm{EM} / \mathrm{kg}$ ) and T6: basal diet 
+ Allzyme ${ }^{\circledR}$ SSF (on top). Dietary treatments were a corn-soybean meal diet, with the inclusion of do Allzyme ${ }^{\circledR}$ SSF $(150 \mathrm{~g} / \mathrm{t})$. Evaluated variables were feed intake (CR), daily egg production (PDOV), feed conversion (CADZ, feed/dozen eggs), body weight (PC), body weight variation (PVPC), egg weight (POV), specific gravity (GE), egg yolk colour (CG), Haugh units (UH), albumen weight $(P C L)$, Yolk weight $(P G)$, shell weight (PCS), shell thickness (ECS) and bone strength (RO). Data were evaluated using ANOVA and Tukey test to separate the means $(5 \%)$ and simple and multiple contrasts analysis. Birds fed T6 showed lower egg weight and albumen weight. The remaining variables were not affected by dietary treatments. These results indicate that adding Allzyme ${ }^{\circledR}$ SSF on top of a diet brings about a reduction in consumption, without affecting egg production and bone strength.

\section{INTRODUÇÃO}

A inclusão de aditivos enzimáticos nas rações tem apresentado grande potencial para a indústria de produção animal. Atualmente, elas podem ser empregadas de várias maneiras e com diferentes objetivos, tais como redução de fatores antinutricionais e aumento de digestibilidade dos alimentos (Fernandes e Malaguido, 2004).

Alguns países da Europa têm obtido êxito com a utilização de enzimas exógenas nas rações animais. Nesses países, as principais fontes de energia para rações de aves são cereais, como trigo, cevada, centeio e aveia, e grãos, que possuem baixa disponibilidade de energia e são ricos em polissacarídeos não-amídicos, os quais são praticamente indigeridos pelas aves (Freitas et al., 2000). Com o uso de enzimas exógenas há um melhor aproveitamento dos nutrientes podendo representar uma economia significativa no custo final das rações.

Em geral, as enzimas exógenas são utilizadas na alimentação animal com dois objetivos bem definidos: complementar a ação das enzimas que são produzidas pelo próprio animal em quantidades insuficientes como as amilases e proteases; e, fornecer aos animais enzimas que eles não conseguem sintetizar como as celulases (Nocera, 2005).

Trabalhos recentes têm demonstrado respostas positivas quanto à digestibilidade de nutrientes e desempenho de aves e suínos alimentados com rações à base de milho e farelo de soja quando suplementadas por enzimas exógenas.

Viveros et al. (2002) verificaram que a inclusão de fitase (500 FTU/kg) na dieta de frangos de corte melhorou em $6,3 \%$ o ganho de peso. A retenção de fósforo aumentou em 10,1\% no mesmo período e a retenção de cálcio, magnésio e zinco aumentou, respectivamente, 15, 23 e 93,6\%. Além disso, a excreção de fósforo foi reduzida em $6,3 \% \mathrm{e}$ de cálcio em 2,7\% nos frangos que se alimentaram com dietas com baixo P total suplementadas com a enzima.

Acevedo (2005) enfatiza que o uso de enzimas exógenas representa uma alternativa interessante. Quando os conhecimentos sobre a fisiologia digestiva das aves e composição química dos ingredientes mostram que a capacidade de aproveitamento dos nutrientes pode ser melhorada de maneira prática, através da correta utilização destas ferramentas biotecnológicas. Assim, a utilização de enzimas representa uma possibilidade de tornar mais versáteis as formulações das dietas, permitindo a inclusão de determinados ingredientes que apresentam limitações em função da presença de componentes de baixa digestibilidade ou fatores antinutricionais. Segundo o mesmo autor, outro aspecto que tem favorecido o desenvolvimento e a utilização dos complexos enzimáticos é a crescente pressão exercida pelos consumidores em reduzir a eliminação de contaminantes para o meio ambiente, principalmente através das excretas, tais como o fósforo, nitrogênio, cobre e zinco e eliminar o uso de antibióticos da dieta.

O Allzyme ${ }^{\circledR}$ SSF é um complexo multienzimático produzido pela Alltech do Brasil Agroindustrial Ltda., a partir de fungo Aspergillus niger, não geneticamente modificado, capaz de aumentar a disponi- 


\section{EFEITO DO ALLZYME® SSF NA DIETA DE POEDEIRAS}

bilidade da energia, da proteína, dos aminoácidos, do fósforo e do cálcio. É composto por sete diferentes enzimas: fitase, protease, xilanase, ß-glucanase, celulase, amilase e pectinase. Cada enzima atua sobre substratos específicos, como exemplos, fitase atua sobre o ácido fítico, protease sobre proteínas e celulase sobre celulose. Isto faz com que estes substratos sejam melhor aproveitados pelo animal.

Objetivou-se avaliar a contribuição do complexo enzimático Allzyme ${ }^{\circledR}$ SSF com diferentes níveis de valorização energética na dieta sobre o desempenho produtivo, a qualidade dos ovos e a resistência óssea de poedeiras semipesadas.

\section{MATERIAL E MÉTODOS}

Durante o período de agosto de 2006 a maio 2007, realizou-se um ensaio no aviário experimental do Conjunto Agrotécnico Visconde da Graça(CAVG), da Universidade Federal de Pelotas. UFPel, Pelotas, RS, Brasil, que totalizou 280 dias experimentais, divididos em dez ciclos de 28 dias cada.

Foram utilizadas 384 poedeiras, da linhagem Hisex Brown, com idade inicial de

Tabela I. Composição das dietas experimentais fornecidas durante o período de 26 a 42 semanas de idade das aves. (Composition of experimental diets fed to layers ( 26 to 42 weeks of age)).

\begin{tabular}{|c|c|c|c|c|c|c|}
\hline Ingredientes (kg) & $\begin{array}{c}\mathrm{T} 1 \\
\text { Controle }\end{array}$ & $\begin{array}{c}\text { T2 } \\
120 \mathrm{kcal}\end{array}$ & $\begin{array}{c}\text { T3 } \\
90 \text { kcal }\end{array}$ & $\begin{array}{c}\text { T4 } \\
60 \text { kcal }\end{array}$ & $\begin{array}{c}\text { T5 } \\
30 \text { kcal }\end{array}$ & $\begin{array}{c}\text { T6 } \\
0 \text { kcal }\end{array}$ \\
\hline Milho & 628,90 & 573,05 & 586,45 & 600,55 & 615,05 & 628,55 \\
\hline Farelo de soja & 248,00 & 223,00 & 227,00 & 231,00 & 235,00 & 240,00 \\
\hline Farelo de trigo & 7,10 & 92,20 & 74,70 & 56,60 & 38,10 & 19,60 \\
\hline Ostra $36 \%$ & 77,00 & 78,00 & 78,00 & 78,00 & 78,00 & 78,00 \\
\hline Sal & 3,60 & 3,60 & 3,70 & 3,70 & 3,70 & 3,70 \\
\hline Fosfato bicálcico & 5,40 & - & - & - & - & - \\
\hline Núcleo 193P1¹ & 30,00 & 30,00 & 30,00 & 30,00 & 30,00 & 30,00 \\
\hline Allzyme ${ }^{\circledR}$ SSF & - & 0,150 & 0,150 & 0,150 & 0,150 & 0,150 \\
\hline Total & 1000,00 & 1000,00 & 1000,00 & 1000,00 & 1000,00 & 1000,00 \\
\hline \multicolumn{7}{|l|}{ Níveis nutricionais calculados } \\
\hline Energia metabolizável (kcal/kg) & 2720,00 & 2720,00 & 2720,00 & 2720,00 & 2720,00 & 2720,00 \\
\hline Proteína bruta (\%) & 16,60 & 16,61 & 16,60 & 16,60 & 16,62 & 16,65 \\
\hline Cálcio (\%) & 3,80 & 3,81 & 3,80 & 3,80 & 3,80 & 3,80 \\
\hline Fósforo total (\%) & 0,68 & 0,63 & 0,62 & 0,61 & 0,60 & 0,59 \\
\hline Fósforo disponível (\%) & 0,48 & 0,49 & 0,49 & 0,49 & 0,48 & 0,48 \\
\hline Aminoácidos sulfurados totais (\%) & 0,64 & 0,66 & 0,66 & 0,66 & 0,66 & 0,66 \\
\hline Metionina total $(\%)$ & 0,36 & 0,36 & 0,36 & 0,36 & 0,36 & 0,36 \\
\hline Lisina total $(\%)$ & 0,89 & 0,89 & 0,89 & 0,90 & 0,90 & 0,91 \\
\hline Colina total (mg/kg) & 1080,23 & 1083,19 & 1081,42 & 1080,05 & 1080,00 & 1080,00 \\
\hline Ácido linolêico (\%) & 1,59 & 1,60 & 1,61 & 1,61 & 1,61 & 1,61 \\
\hline Gordura bruta (\%) & 2,73 & 2,82 & 2,81 & 2,79 & 2,78 & 2,76 \\
\hline Fibra bruta (\%) & 2,97 & 3,49 & 3,38 & 3,27 & 3,15 & 3,04 \\
\hline Sódio total (\%) & 0,18 & 0,18 & 0,18 & 0,18 & 0,18 & 0,18 \\
\hline
\end{tabular}

${ }^{1}$ Composição (garantia por kg): 269 g Ca; 94 g P; 334000 Ul vit. A; 67000 UI vit. D3; 234 UI vit. E; 50 mg vit. K3; 54 mg vit. B1; 147 mg vit. B2; 100 mg vit B6; 400 mg vit B12; 867 mg niacina; 334 ácido pantotênico; 24 mg ácido fólico; 34 g Met; 2334 mg Mn; 1667 mg Zn; 2000 mg Fe; 334 mg Co; 12 mg I; 10,2mg Se. 
Tabela II. Composição das dietas experimentais fornecidas durante o período de 42 a 66 semanas de idade das aves. (Composition of experimental diets fed to layers (42 to 66 weeks of age)).

\begin{tabular}{|c|c|c|c|c|c|c|}
\hline Ingredientes (kg) & $\begin{array}{c}\mathrm{T} 1 \\
\text { Controle }\end{array}$ & $\begin{array}{c}\text { T2 } \\
120 \text { kcal }\end{array}$ & $\begin{array}{c}\text { T3 } \\
90 \mathrm{kcal}\end{array}$ & $\begin{array}{c}\text { T4 } \\
60 \mathrm{kcal}\end{array}$ & $\begin{array}{c}\text { T5 } \\
30 \mathrm{kcal}\end{array}$ & $\begin{array}{c}\text { T6 } \\
0 \text { kcal }\end{array}$ \\
\hline Milho & 630,50 & 575,55 & 589,05 & 602,55 & 616,15 & 630,55 \\
\hline Farelo de soja & 233,00 & 208,00 & 213,00 & 218,00 & 223,00 & 227,00 \\
\hline Farelo de trigo & 13,40 & 98,70 & 80,20 & 61,70 & 43,10 & 24,60 \\
\hline Ostra $36 \%$ & 84,00 & 84,00 & 84,00 & 84,00 & 84,00 & 84,00 \\
\hline Sal & 3,60 & 3,60 & 3,60 & 3,60 & 3,60 & 3,70 \\
\hline Fosfato bicálcico & 5,50 & - & - & - & - & - \\
\hline Núcleo 193P21 & 30,00 & 30,00 & 30,00 & 30,00 & 30,00 & 30,00 \\
\hline Allzyme SSF ${ }^{\circledR}$ & - & 0,150 & 0,150 & 0,150 & 0,150 & 0,150 \\
\hline Total & 1000,00 & 1000,00 & 1000,00 & 1000,00 & 1000,00 & 1000,00 \\
\hline \multicolumn{7}{|l|}{ Níveis nutricionais calculados } \\
\hline Energia metabolizável (kcal/kg) & 2700,00 & 2700,00 & 2700,00 & 2700,00 & 2700,00 & 2700,00 \\
\hline Proteína bruta (\%) & 16,00 & 16,04 & 16,06 & 16,08 & 16,11 & 16,13 \\
\hline Cálcio (\%) & 4,05 & 4,05 & 4,05 & 4,05 & 4,05 & 4,05 \\
\hline Fósforo total $(\%)$ & 0,68 & 0,63 & 0,62 & 0,61 & 0,59 & 0,58 \\
\hline Fósforo disponível (\%) & 0,48 & 0,49 & 0,49 & 0,48 & 0,48 & 0,48 \\
\hline Aminoácidos sulfurados totais (\%) & 0,60 & 0,62 & 0,62 & 0,62 & 0,62 & 0,62 \\
\hline Metionina total $(\%)$ & 0,32 & 0,33 & 0,33 & 0,33 & 0,33 & 0,33 \\
\hline Lisina total $(\%)$ & 0,85 & 0,85 & 0,86 & 0,86 & 0,87 & 0,87 \\
\hline Colina total (mg/kg) & 1053,30 & 1050,00 & 1050,00 & 1050,00 & 1050,00 & 1050,00 \\
\hline Ácido linolêico (\%) & 1,60 & 1,61 & 1,61 & 1,61 & 1,61 & 1,61 \\
\hline Gordura bruta (\%) & 2,74 & 2,83 & 2,81 & 2,80 & 2,78 & 2,77 \\
\hline Fibra bruta (\%) & 2,94 & 3,46 & 3,35 & 3,23 & 3,12 & 3,01 \\
\hline Sódio total (\%) & 0,18 & 0,18 & 0,18 & 0,18 & 0,18 & 0,18 \\
\hline
\end{tabular}

${ }^{1}$ Composição (garantia por kg): 267 g Ca; 99 g P; 985 mg F; 334000 UI vit. A; 67000 UI vit. D3; 234 UI vit. E; 50 mg vit. K3; $54 \mathrm{mg}$ vit. B1; $147 \mathrm{mg}$ vit. B2; $100 \mathrm{mg}$ vit B6; $400 \mathrm{mg}$ vit B12; $867 \mathrm{mg}$ niacina; 334 ácido pantotênico; 24 mg ácido fólico; 34 g Met; 2334 mg Mn; 1667 mg Zn; 2000 mg Fe; 334 mg Co; 20 $\mathrm{mg} \mathrm{I} ; 10 \mathrm{mg} \mathrm{Se}$.

26 semanas e peso médio inicial de 1533 gramas. As aves foram mantidas em galpão tipo dark house, alojadas em gaiolas de postura, dispostas em dois andares, contendo quatro aves cada. As poedeiras foram distribuídas nos tratamentos em um delineamento completamente ao acaso, com 16 repetições/tratamento. Os tratamentos consistiram em fornecer dietas reformuladas para valorizar a energia metabolizável, da seguinte forma: T1: dieta basal (controle); T2: dieta basal + Allzyme ${ }^{\circledR}$ SSF (valorizado em $120 \mathrm{kcal} \mathrm{EM} / \mathrm{kg})$; T3: dieta basal + Allzyme ${ }^{\circledR}$ SSF (valorizado em 90 kcal EM/ $\mathrm{kg}$ ); T4: dieta basal + Allzyme ${ }^{\circledR}$ SSF (valorizado em $60 \mathrm{kcal} \mathrm{EM} / \mathrm{kg}$ ); T5: dieta basal + Allzyme ${ }^{\circledR} \mathrm{SSF}$ (valorizado em $30 \mathrm{kcalEM} / \mathrm{kg}$ ) e T6: dieta basal + Allzyme ${ }^{\circledR}$ SSF (sem valorização energética). As dietas eram isoenergéticas, isoprotéicas, isominerais e isovitamínicas, tendo o complexo enzimático Allzyme ${ }^{\circledR}$ SSF sido incluído na matriz nutricional das dietas de acordo com a indicação do fabricante $(150 \mathrm{~g} / \mathrm{t})$. As tabelas I e II mostram as composições das dietas experimentais nos períodos de 26 a 42 semanas e 43 a 66 semanas de idade das aves, respectivamente, de acordo com o manual 


\section{EFEITO DO ALLZYME® SSF NA DIETA DE POEDEIRAS}

da linhagem e tabelas brasileiras.

As aves foram alimentadas à vontade, utilizando-se comedouros do tipo calha aberta, dispostos na frente das gaiolas, e isolados por divisórias para que a ração fosse fornecida para cada unidade experimental, separadamente.

A água foi fornecida através de bebedouros tipo nipple, à vontade, de maneira que as aves de cada gaiola tivessem acesso a dois bebedouros. O regime de luz seguiu as orientações estabelecidas pelo manual da linhagem com dezesseis horas e trinta minutos de luz diária.

A temperatura interna do galpão foi registrada pela observação de um termômetro de mínima e máxima, tendo oscilado, durante o período experimental, entre $14,6^{\circ} \mathrm{C}$ a $22,0^{\circ} \mathrm{C}$. O sistema de ventilação do ambiente foi realizado com o uso de exaustores, loca- lizados no centro do galpão, acionados através de termostatos. Além disso, a saída de ar ocorria através de aberturas localizadas em ambos os lados dos exaustores e para a entrada de ar no interior do galpão eram utilizadas aberturas, em ambas as laterais. Os dejetos das aves mantidas no galpão foram recolhidos à medida que se liquefaziam através de drenos para um fosso localizado no lado externo da instalação.

As variáveis de desempenho analisadas foram consumo de ração (CR), produção diária de ovos (PDOV), conversão alimentar por dúzia (CADZ), peso corporal (PC) e variação do peso corporal (VPC). Estas variáveis foram analisadas dentro de cada período de 28 dias, sendo que as variáveis CR e PDOV tiveram controle diário.

A cada 28 dias utilizou-se em média 44 ovos/tratamento/ciclo para as análises re-

Tabela III. Médias das variáveis de desempenho consumo de ração (CR - g), produção diária de ovos (PDOV), conversão alimentar por dúzia (CADZ), peso corporal (PC) e variação do peso corporal (VPC) por ave, para cada nível de valorização energética do Allzyme ${ }^{\circledR} S S F$. (Feed intake (CR - g), egg production (PDOV), feed conversion (CADZ), body weight (PC) and body weight variation (VPC) of layers fed diets energetically overestimated and containing Allzyme ${ }^{\circledR}$ SSF).

\begin{tabular}{|c|c|c|c|c|c|}
\hline $\begin{array}{l}\text { Allzyme }{ }^{\circledR} \text { SSF } \\
(\text { kcal EM/kg SSF) }\end{array}$ & CR & PDOV & CADZ & $\mathrm{PC}$ & VPC \\
\hline Sem SSF (T1) $(n=64)$ & $115,21^{a}$ & 48,17 & 2,88 & 1820,15 & 128,15 \\
\hline $120(T 2)(n=64)$ & $120,14^{a}$ & 50,08 & 2,93 & 1751,75 & 81,83 \\
\hline $90($ T3) $(n=64)$ & $119,69^{a}$ & 49,57 & 2,95 & 1735,00 & 44,86 \\
\hline $60(T 4)(n=64)$ & $117,99^{a}$ & 48,50 & 2,99 & 1771,88 & 88,38 \\
\hline $30(T 5)(n=64)$ & $116,73^{a}$ & 46,06 & 3,06 & 1776,19 & 76,75 \\
\hline $0(T 6)(n=64)$ & $108,22^{b}$ & 48,08 & 2,69 & 1742,23 & 69,85 \\
\hline $\mathrm{p}$ & 0,0063 & 0,6705 & 0,1203 & 0,0501 & 0,0646 \\
\hline CV (\%) & 7,22 & 13,81 & 11,69 & 0,13 & 83,29 \\
\hline Erro padrão & 8,41 & 6,67 & 0,34 & 73,84 & 67,68 \\
\hline \multicolumn{6}{|l|}{ Contraste simples (p) } \\
\hline T1 vs. T2 & 0,1550 & 0,4839 & 0,7166 & 0,0233 & 0,0913 \\
\hline T1 vs. T3 & 0,1795 & 0,5942 & 0,6183 & 0,0037 & 0,0020 \\
\hline T1 vs. T4 & 0,3903 & 0,8963 & 0,4118 & 0,0839 & 0,1195 \\
\hline T1 vs. T5 & 0,6384 & 0,4116 & 0,1788 & 0,1149 & 0,0454 \\
\hline T1 vs. T6 & 0,0410 & 0,9733 & 0,1814 & 0,0087 & 0,0310 \\
\hline \multicolumn{6}{|l|}{ Contraste múltiplo (p) } \\
\hline $\mathrm{T} 1$ vs. $\mathrm{T} 2+\mathrm{T} 3+\mathrm{T} 4+\mathrm{T} 5+\mathrm{T} 6$ & 0,6112 & 0,8889 & 0,6837 & 0,0048 & 0,0078 \\
\hline
\end{tabular}

${ }^{a b}$ Médias na mesma coluna com letras distintas diferem pelo teste Tukey $(p<0,05)$. 
ferentes às variáveis de qualidade externa e interna dos ovos, ou seja, peso dos ovos (POV), gravidade específica (GE), coloração de gema (CG), altura de clara (ACL), peso da clara (PCL), peso da gema (PG), peso da casca (PCS) e espessura da casca (ECS). Depois de obtidos os valores referentes ao POV e ACL calculou-se a unidade Haugh dos ovos (UH). A massa dos ovos (MOV) foi obtida através das variáveis PDOV e POV.

Ao final do período experimental foram abatidas duas aves de cada tratamento, retirando-se os ossos da tíbia dos membros direito e esquerdo. Estes ossos foram mantidos sob refrigeração e após foram levados para a análise de resistência óssea utilizando-se o equipamento Instron Universal Testing Machine (MOD. 1130). Para a medida de resistência dos ossos da tíbia utilizou-se uma célula larga, plana, de pistão chato com diâmetro de $24 \mathrm{~mm}$, com calibre de $50 \mathrm{~kg}$. A velocidade da carga e cabeça para a leitura dos resultados foi de $10 \mathrm{~cm} / \mathrm{min}$, sendo o primeiro pico representado pela força de compressão em quilogramas, que representa a resistência do osso à compressão.

Os dados foram submetidos à análise estatística utilizando análise de variância a 5\% de probabilidade e teste Tukey. Realizouse também a análise de contrastes simples e múltiplo.

\section{RESULTADOSEDISCUSSÃO}

Os dados produtivos são mostrados na tabela III. Observou-se uma redução significativa no CR para as aves que receberam

Tabela IV. Médias das variáveis de qualidade externa dos ovos peso dos ovos (POV), gravidade específica (GE), peso da casca (PCS), espessura da casca (ECS) e massa dos ovos $(\mathrm{MOV})$, durante dez ciclos de produção, para cada nível de valorização energética do Allzyme ${ }^{\circledR} S S F$. (Egg weight (POV), specific gravity (GE), eggshell weight (PCS), eggshell thickness (ECS), egg mass (MOV), of eggs from layers fed diets energetically overestimated and containing Allzyme ${ }^{\circledR} \mathrm{SSF}$ ).

\begin{tabular}{|c|c|c|c|c|c|}
\hline $\begin{array}{l}\text { Allzyme }^{\circledR} \text { SSF } \\
(\text { kcal EM/kg SSF })\end{array}$ & POV & GE & PCS & ECS & MOV \\
\hline Sem SSF (T1) $(n=64)$ & $62,43^{\mathrm{ab}}$ & 1091,00 & 5,94 & 39,99 & 30,02 \\
\hline $120(T 2)(n=64)$ & $60,88^{\mathrm{bc}}$ & 1091,50 & 5,87 & 39,93 & 30,45 \\
\hline $90($ T3) $(n=64)$ & $62,81^{a}$ & 1091,43 & 6,08 & 40,41 & 31,05 \\
\hline $60(T 4)(n=64)$ & $61,08^{b c}$ & 1091,38 & 5,90 & 40,02 & 29,55 \\
\hline 30 (T5) $(n=64)$ & $62,58^{\mathrm{ab}}$ & 1091,25 & 6,03 & 40,23 & 28,86 \\
\hline $0(T 6)(n=64)$ & $60,30^{c}$ & 1092,62 & 5,87 & 40,78 & 28,96 \\
\hline $\mathrm{p}$ & 0,0237 & 0,3076 & 0,2085 & 0,4099 & 0,5992 \\
\hline CV (\%) & 3,80 & 0,17 & 4,57 & 2,87 & 12,59 \\
\hline Erro padrão & 2,34 & 1,83 & 0,27 & 1,15 & 3,75 \\
\hline \multicolumn{6}{|l|}{ Contraste simples } \\
\hline T1 vs. T2 & 0,1092 & 0,5057 & 0,5353 & 0,8907 & 0,7819 \\
\hline T1 vs. T3 & 0,6838 & 0,5537 & 0,1805 & 0,3634 & 0,4881 \\
\hline T1 vs. T4 & 0,1304 & 0,5934 & 0,7236 & 0,9666 & 0,7424 \\
\hline T1 vs. T5 & 0,8732 & 0,7117 & 0,3989 & 0,5939 & 0,4200 \\
\hline T1 vs. T6 & 0,0257 & 0,0306 & 0,5234 & 0,0952 & 0,4816 \\
\hline \multicolumn{6}{|l|}{ Contraste múltiplo (p) } \\
\hline $\mathrm{T} 1$ vs. $\mathrm{T} 2+\mathrm{T} 3+\mathrm{T} 4+\mathrm{T} 5+\mathrm{T} 6$ & 0,2193 & 0,2714 & 0,8938 & 0,4446 & 0,8327 \\
\hline
\end{tabular}

${ }^{a b}$ Médias na mesma coluna com letras distintas diferem pelo teste Tukey $(p<0,05)$.

Archivos de zootecnia vol. 58, núm. 224, p. 650. 


\section{EFEITO DO ALLZYME® SSF NA DIETA DE POEDEIRAS}

dieta contendo Allzyme ${ }^{\circledR}$ SSF sem valorização energética, ou seja, on top (T6). Consta-tou-se que o consumo foi significativamente menor quando o grupo controle foi contrastado com o grupo T6 que recebeu o complexo enzimático on top. Já a variação da valorização energética do Allzyme ${ }^{\circledR} \mathrm{SSF}$ não afetou, significativamente, as variáveis PDOV e CADZ. Entretanto, as médias do grupo controle (T1) apresentaram um PC maior ao final dos 10 ciclos produtivos avaliados, comparativamente, as médias do T2, T3 e T6 como observado na análise de contraste simples, assim como quando as médias do T1 foram contrastadas com todas as médias do conjunto dos tratamentos com Allzyme ${ }^{\circledR}$ SSF como verificado na análise de contraste múltiplo.

Na mesma tabela, na análise de contraste simples da variável VPC, observou-se que o grupo controle (T1) apresentou um ganho significativo de peso corporal quando contrastado com T3, T5 e T6, que obtiveram um menor ganho de peso. Esta mesma diferença foi observada na análise de contraste múltiplo quando as médias do grupo que não recebeu complexo enzimático na dieta foram contrastadas com as médias dos demais grupos.

A atuação do complexo enzimático sobre os ingredientes da dieta, provavelmente tenha promovido a liberação de energia, fazendo com que as aves tenham reduzido o consumo de ração. Leeson e Summers (1997), citados por Stringhini et al. (2005), enfatizam que poedeiras comerciais regulam o consumo de ração de forma bastante eficiente de acordo com a quantidade de energia. Outros autores como Wyatt (1990); Jaroni et al. (1999) e Geraldo et al. (2006), ao fornecerem

Tabela $\boldsymbol{V}$. Médias das variáveis de qualidade interna dos ovos unidade Haugh (UH), peso da clara (PCL), peso da gema (PG) e coloração de gema $(C G)$, durante dez ciclos de produção, para cada nível de valorização energética do Allzyme ${ }^{\circledR} S S F$. (Haugh units (UH), albumen weight $(P C L)$, yolk weight $(P G)$, yolk color $(C G)$ of eggs from hens fed energetically overestimated diets, containing Allzyme ${ }^{\circledR}$ SSF).

\begin{tabular}{lcccc}
\hline $\begin{array}{l}\text { Allzyme } \\
\text { (kcal EM/kg SSF) }\end{array}$ & UH & PCL & PG & CG \\
\hline Sem SSF (T1) $(n=64)$ & 83,30 & $37,81^{\mathrm{a}}$ & 15,80 & 6,83 \\
$120(\mathrm{~T} 2)(\mathrm{n}=64)$ & 84,88 & $35,66^{\mathrm{b}}$ & 15,87 & 6,50 \\
$90(\mathrm{~T} 3)(\mathrm{n}=64)$ & 82,23 & $37,84^{\mathrm{a}}$ & 15,97 & 6,36 \\
$60(\mathrm{~T} 4)(\mathrm{n}=64)$ & 84,46 & $35,91^{\mathrm{b}}$ & 15,76 & 6,38 \\
30 (T5) $(\mathrm{n}=64)$ & 84,62 & $37,24^{\mathrm{a}}$ & 15,89 & 6,38 \\
0 (T6) $(\mathrm{n}=64)$ & 83,80 & $35,82^{\mathrm{b}}$ & 15,46 & 6,38 \\
$\mathrm{p}$ & 0,1861 & 0,0016 & 0,4952 & 0,1663 \\
CV $(\%)$ & 3,54 & 4,89 & 4,38 & 7,98 \\
Erro padrão & 2,97 & 1,80 & 0,69 & 0,52 \\
Contraste simples $(\mathrm{p})$ & 0,1972 & 0,0045 & 0,7935 & 0,1173 \\
T1 vs. T2 & 0,3644 & 0,9582 & 0,5206 & 0,0214 \\
T1 vs. T3 & 0,3090 & 0,0072 & 0,8943 & 0,0225 \\
T1 vs. T4 & 0,2480 & 0,4099 & 0,7242 & 0,0225 \\
T1 vs. T5 & 0,6753 & 0,0083 & 0,2299 & 0,0327 \\
T1 vs. T6 & & & & \\
Contraste múltiplo $(\mathrm{p})$ & 0,4538 & 0,0222 & 0,9801 & 0,0085 \\
T1 vs. T2+T3+T4+T5+T6 & & & & \\
\hline
\end{tabular}

abMédias na mesma coluna com letras distintas diferem pelo teste Tukey $(p<0,05)$. 
dietas com suplementação enzimática, também verificaram uma significativa redução do consumo de ração, mantendo produção semelhante, quando comparado com aves recebendo outras dietas. Isto demonstra que as enzimas melhoraram o valor energético das dietas, exercendo influência sobre o consumo de ração, e que o Allzyme ${ }^{\circledR}$ SSF, possivelmente, valorize a energia necessária para melhorar o desempenho produtivo das aves que recebem dietas reformuladas.

Nas tabelas IV e V estão demonstrados os dados de qualidade externa e interna dos ovos. As variáveis POV (tabela IV) e PCL (tabela V), tiveram seus valores reduzidos, significativamente, possivelmente, devido ao menor consumo alimentar mensurado nas aves que receberam dieta em que o Allzyme ${ }^{\circledR}$ SSF não teve valorizado sua energia (T6). Na análise de contraste simples para POV observou-se que os ovos do grupo controle (T1) apresentaram peso significativamente maior quando contrastado com os do T6, da mesma forma a variável PCL apresentou diferença na análise de contraste simples com maior peso para os ovos do T1 quando contrastados aos do T2, T4 e T6, assim como quando contrastado com todos os tratamentos que continham complexo enzimático na sua composição. A possível liberação de energia promovida pelo Allzyme ${ }^{\circledR}$ SSF quando adicionado on top na dieta das poedeiras, fez com que as aves consumissem menos, e isto pode ter interferido na ingestão e digestão de proteína e aminoácidos, que são essenciais à formação do ovo. Neste experimento os níveis de proteína não foram corrigidos nos tratamentos com maior valorização da energia liberada pelo complexo enzimático. Devido a isso, as aves desse tratamento produziram ovos mais leves e com claras também mais leves, entretanto, mesmo com peso do ovo menor, estes atingiram o peso médio esperado para sua comercialização. Estes resultados corroboram com Leeson (1996), quando relata que em condições
Tabela VI. Médias da variável resistência óssea- tíbia (RO), para cada nível de valorização energética do Allzyme ${ }^{\circledR}$ SSF. (Tibiotarsus strength (RO) of layers fed energetically overestimated diets, containing Allzyme SSF).

\begin{tabular}{lc}
\hline $\begin{array}{l}\text { Allzyme } \\
\text { (kcal EM/kg SSF) }\end{array}$ & RO $(\mathrm{kgf} / \mathrm{mm})$ \\
\hline Sem SSF (T1) & 12,70 \\
120 (T2) & 14,65 \\
$90(\mathrm{~T} 3)$ & 12,85 \\
60 (T4) & 12,35 \\
30 (T5) & 14,80 \\
0 (T6) & 13,95 \\
$\mathrm{p}$ & 0,5806 \\
CV (\%) & 17,73 \\
Erro padrão & 2,40 \\
Contraste simples (p) & \\
T1 vs. T2 & 0,2659 \\
T1 vs. T3 & 0,9306 \\
T1 vs. T4 & 0,8390 \\
T1 vs. T5 & 0,2322 \\
T1 vs. T6 & 0,4712 \\
Contraste múltiplo $(p)$ & \\
T1 vs. T2+T3+T4+T5+T6 & 0,4482 \\
\hline
\end{tabular}

normais o nível de energia não influencia o tamanho do ovo, sendo o teor de proteína da dieta o principal fator responsável por esta variação.

Por outro lado as variáveis PCS, ECS e MOV (tabela IV), e UH, PG e CG (tabela V) não sofreram efeito significativo das diferentes valorizações energéticas do complexo enzimático.

A resistência óssea não diferiu estatisticamente entre os tratamentos (tabela VI). Isto significa que houve liberação de fósforo da dieta, de forma a incorporar nos ossos (fosfato de cálcio), uma vez que se partiu do princípio de que em todas as dietas (exceto o controle), houve a disponibilização $0,1 \% \mathrm{deP}$, por ação da fitase contida no Allzyme ${ }^{\circledR} \mathrm{SSF}$.

Dados semelhantes foram observados por Qiugang et al. (2004), que avaliando o Allzyme ${ }^{\circledR}$ SSF no desempenho e disponibilidade de fósforo em poedeiras, verificaram 


\section{EFEITO DO ALLZYME®SSF NA DIETA DE POEDEIRAS}

que não houve efeito significativo, sobre o comprimento e resistência da tíbia, peso das cinzas e conteúdo de cálcio da tíbia.

Investigações realizadas por Corn(1999), citado por Miles (1999), mostram que as enzimas agregadas a dietas baseadas em milho e farelo de soja podem incrementar o conteúdo de energia metabolizável em aproximadamente $4 \%$.

\section{BIBLIOGRAFIA}

Acevedo, J.M. 2005. A Utilidad práctica de las proteases exógenas en la alimentación avícola. Avicultura Profissional, 23: 25-28.

Freitas, E.R., M.F.F. Fuentes e G.B. Espíndola. 2000. Efeito da suplementação enzimática em rações à base de milho/farelo de soja sobre o desempenho de poedeiras comerciais. Rev. Bras. Zootecn., 29: 1103-1109.

Fernandes, P.C.C. e A. Malaguido. 2004. Uso de enzimas em dietas de frangos de corte. Em: Anais da Conferência APINCO. 2004. Campinas/ SP. 1: 117-129.

Geraldo, A., A.G. Bertechini, J.A.G. Brito, R.K. Kato e E.J. Fassani. 2006. Níveis de cálcio e granulometrias do calcário para frangas de reposição no período de 3 a 12 semanas de idade. Rev. Bras. Zootecn., 35: 113-118.

Jaroni, D., S.E. Scheideler, M. Beck and C. Wyatt 1999. The effect of dietary wheat middlings and enzyme supplementation. 1. Late egg production efficiency, egg yields, and egg composition in two strains of leghorn hens. Poult. Sci., 78: 841-847.

Leeson, S. 1996. Programas de alimentación para ponedoras e broilers. En: XII Curso de Especialización FEDNA. Madrid. España. pp. 201-216.

Miles, R.D. 1999. Formulación de alimentos para ponedoras para el futuro. Industria Avícola.

\section{CONCLUSÃO}

O complexo enzimático Allzyme ${ }^{\circledR}$ SSF quando adicionado on top na dieta propiciou redução no consumo da ração e do peso dos ovos. As demais variáveis produtivas avaliadas, a qualidade da casca e a resitência óssea foram mantidas com a utilização deste complexo enzimático.

Jul. pp. 37-43.

Nocera, G.A. 2005. Efeito da fitase e do diâmetro geométrico médio do milho na dieta sobre o desempenho de frangos de corte. Dissertação de Mestrado. Universidade Federal do Paraná. Qiugang, M.A., J. Cheng, Y. Jiuxian, O. Guoba and S. Chunling. 2004. Effect of Allzyme SSF on reproductive performance and phosphorus availability in laying breeder hens. College of Animal Science and Technology. China Agricultural University. China.

Stringhini, J.H., R.M. Jardim Filho, A.A. Pedroso, M.B. Café, F.B Carvalho e M.S. Matos. 2005. Nutrição no período de pré-postura, pico e póspico de poedeiras comerciais. Conferência APINCO 2005 de Ciência e Tecnologia Avícolas. Anais. Campinas/SP. 2: 171-189.

Viveros, A., A. Brenes, I. Arija and C. Centeno. 2002. Effects of microbial phytase supplementation on mineral utilization and serum enzyme activities in broiler chicks fed different levels of phosphorus. Poult. Sci., 81: 1172-1183.

Wyatt, C.L. 1990. The utilization of barley in laying hen rations: an update on energy content of barley and effects on egg cholesterol. Proceedings $25^{\text {th }}$ Pacific Northwest Animal Nutrition Conference. Las Vegas. pp. 13-27. 